\title{
On the System of Management Process Indices in Building Sector Enterprises
}

\author{
Roman Chernov ${ }^{1}$, Svetlana Shilkina, ${ }^{1, *}$ \\ ${ }^{1}$ Moscow State University of Civil Engineering, 26 Yaroslavskoye Highway, Moscow, Russian \\ Federation, 129337
}

\begin{abstract}
Analyzing the structure of the management process indices in building sector enterprises. Quality level of the system of enterprises managing in the building sector.
\end{abstract}

\section{Introduction to the subject}

In our opinion, the set of indices for the management process in building sector enterprises shall depend upon the system's three main factors: its performance results, resources used in the course of such performance and management system's functioning quality.

First of all, let us dwell upon the results. It is not our intention to deem the number of adopted managerial decisions as such. Moreover, we are sure that the indices characterizing the performance result of the management system for an economic entity in the building sector shall be such object's performance indicators, i.e. the scope, structure and quality of the products and services manufactured and performed by it and the efficiency of resources using.

Speaking of resources, their structure and scope shall depend upon the components and needs of the management system and, as a rule shall include the elements as follows: methods, information, personnel, right, technique, technology, living environment. Each of the aforementioned shall be in kind (real number) and in value terms. Sometimes they are referred to as supporting subsystems.

In its turn each and every supporting subsystem shall be characterized by its performance results, required resources scope and components, and the quality and efficiency of the services being rendered. For instance, the subsystem of information support shall collect, store, process and provide to the management system's employees any and all necessary information in due time and required form. The goal of legal coverage subsystem is observing the managerial decisions legal purity. For this purpose, they shall have their own personnel, methods, and finance at last. And all such elements with their specific indices shall be the elements of the management system. This is also true about any other supporting subsystem. Thus, the complex of indices characterizing the management system's resources shall include the aggregate of all performance indices of all supporting subsystems.

${ }^{*}$ Corresponding author shilkina@bk.ru 


\section{Methods of making management decisions}

Here it is pertinent to draw your attention to one of supporting subsystems, namely the technology of managerial decisions making. Such subsystem had some bad luck. It is rarely if ever and rather passingly is mentioned in the publications dedicated to management theory and practice. For some reason everyone supposes that if one has the information and personnel, is aware of the methods to transform it into managerial decisions, nothing shall prevent the management system's appropriate functioning. However, let us imagine the situation when instead of such system's resigned employee a new one comes. In order to get on the inside he shall need the manager's and colleagues' advice and hints, let alone the time. Being aware of the human nature, we may be sure that such hints more than seldom show right way to go. All these may lead and as often as not actually lead to both current failures in the whole system's functioning and long-term conflicts among the staff by no means improving the efficiency of functioning thereof.

This is where the role of technological support steps forward, providing for each manager's workplace a developed instruction for routine problems solving. It specifies where, when and what information may be received to settle a task, when, who to and what information shall be delivered following the results of settling thereof. And the matter of methods choosing to settle such tasks shall be the employee's responsibility.

Let us pass on to the management system's quality level. Here it is appropriate to formulate our interpretation of this definition. We suppose that the management system's quality shall be characterized by timeliness, scientific and formal validity of managerial decisions being adopted. The formal validity is the compliance of decisions being adopted with the current legal regulations.

The specific values of the management system's quality level shall depend upon the requirements made by contractors, i.e. products and services consumers and resources suppliers. Apart from such contractors, the external environment representatives for the management process are the Russian Ministries and Departments, and superior management authorities, and each of them in its own way influences the management process's indices set and values.

From Russian Ministries and Departments the management process shall receive (fig1):

- technical and sanitary standards and criteria regarding both the products and the processes of manufacturing thereof;

- environmental standards also referring to both the products, and the processes of manufacturing thereof;

- statutory acts determining the special aspects of various kinds of citizens' and legal persons' business activity.

The main goal of the superior management authorities for the process under consideration is to form its milestones.

Finishing to consider the elements of the system of the management process indices we shall analyze its last element being the feedback from the object under management and external environment to the management system.

We remind that the management process consists of the following consequence of its functions: analyzing the state of the object under management, forecasting any possible options of its development, designing the plan of the object's development, informing the executives of the scheduled figures, administering and analyzing the plan implementation. It is quite natural that in the course of performing each of the aforementioned functions we use a certain set of management indices. However, in order to provide continuity when passing from a function to function and to lock in the whole chain from analyzing the plan implementation to analyzing the object's state we shall form a certain indices subset specific all at once for all functions. 


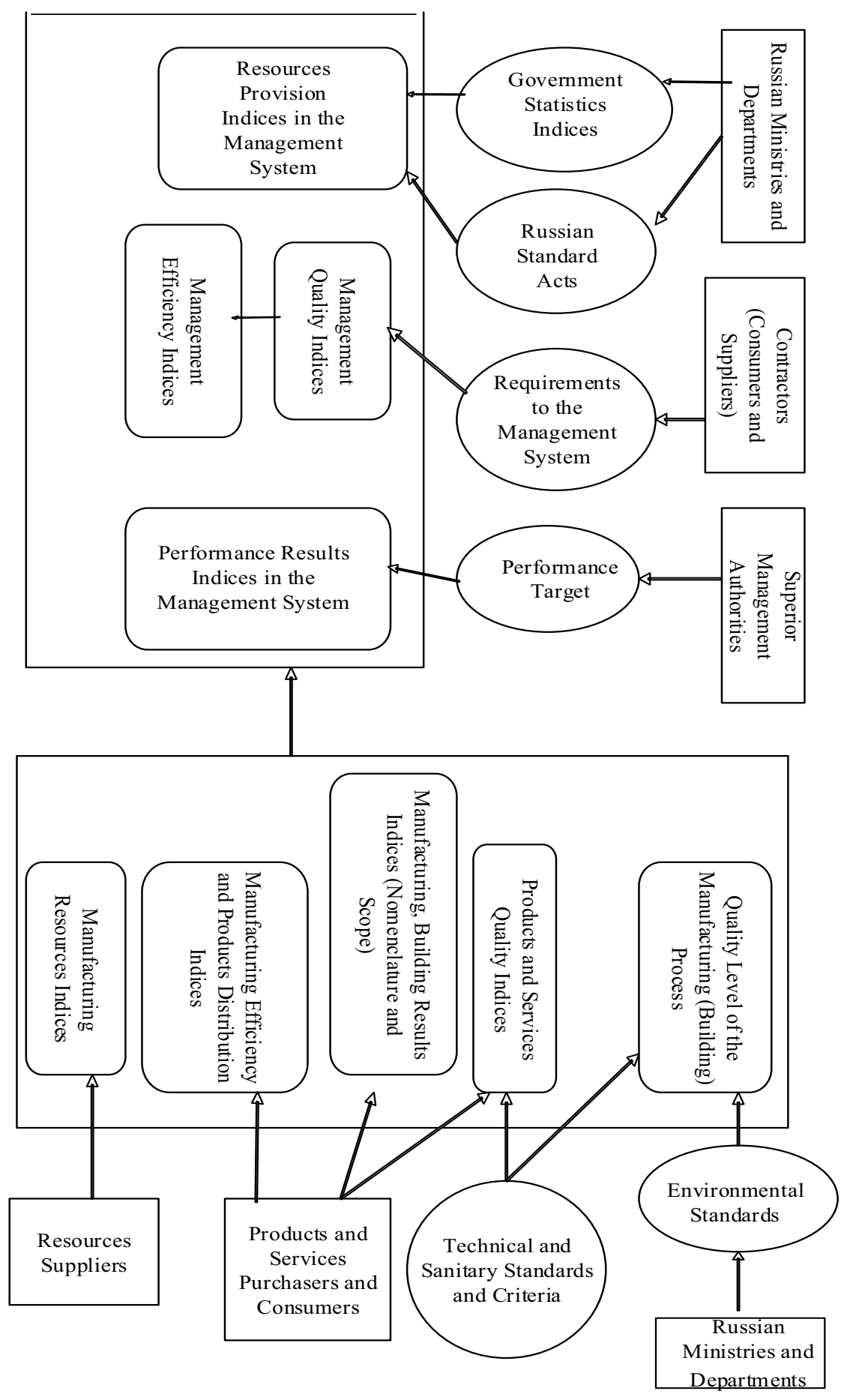

Fig. 1. Structure of the System of the Management Process Indices in Building Sector's Economic Entity. 
The simplified diagram is given in fig. 2. To this particular subset we refer the indices of feedback from the object under management. Their principal goal is to provide to the managers (management subject) in brief, structured from as the complex of indices the most important information enabling to estimate the management process state and make any required decisions. In this case depending on the enterprise's kind and changing external environment the set and elements of the feedback indices may change.

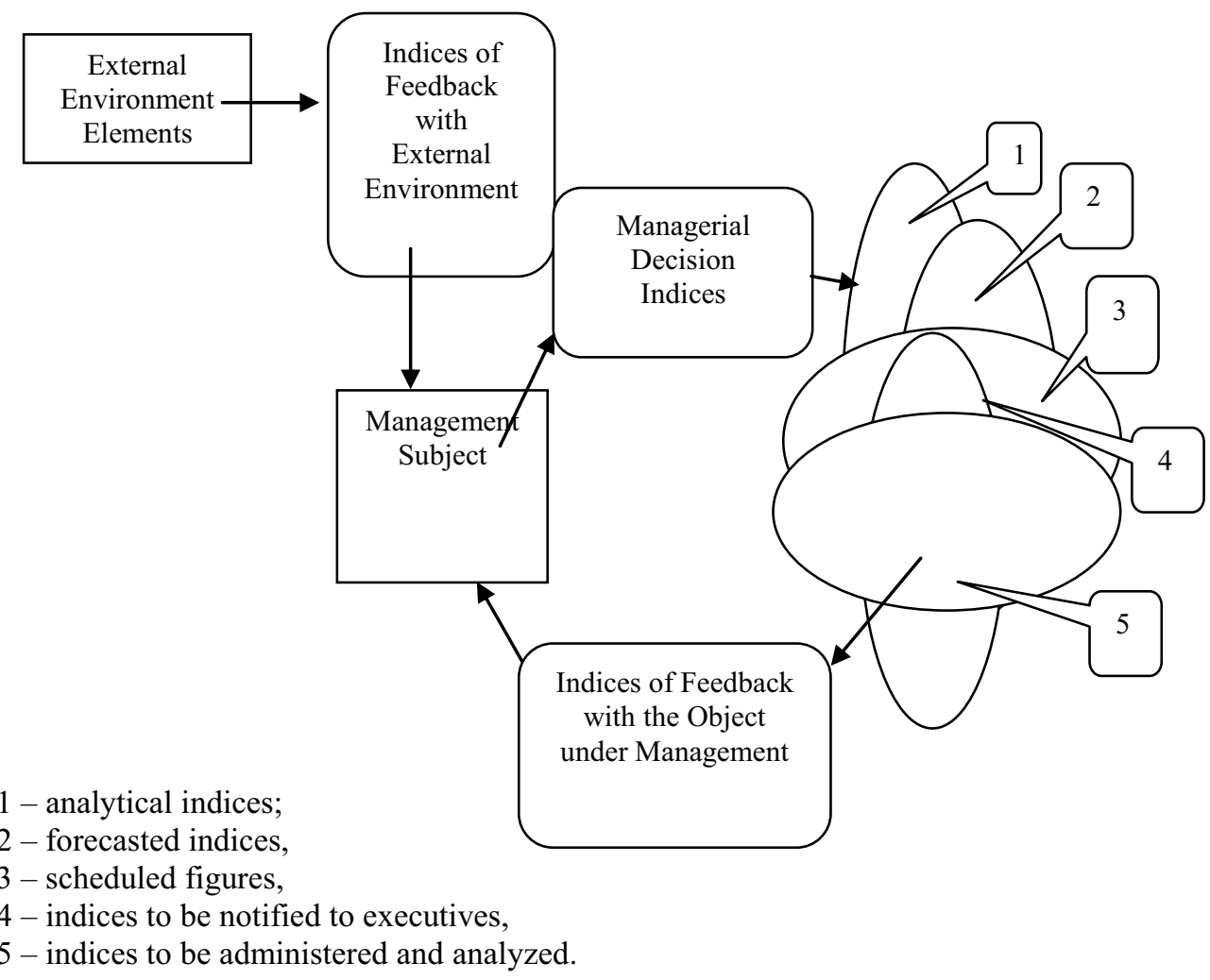

Fig. 2. Scheme of Forming Feedback Indices.

\section{Figures and tables}

At the same time, it is important to emphasize that to make managerial decisions the management subject besides the information regarding the indices of the object under management received via feedback channels shall need to have data on the degree of contractors contentment with the management system's quality. The concept of the indices balanced system (IBS) being so popular over recent years is dedicated exactly to the matters of forming the system of feedback indices in the process of an enterprise managing.

The IBS was developed in the early 1990s by American economists David Norton and Robert Kaplan. According to the developers, such system shall have the information reflecting any and all principal edges of an enterprise's performance. Such information is arranged into four groups reflecting the four performance sphere for a building sector's enterprise:

- financial sphere dealing with the efficiency of the company's activity in the context of return of capital employed and attractiveness for its own shareholders; 
- company's inner potential, inner operating activity development;

- consumers' contentment with the company's goods and services practicability, its corporate image;

- knowledge, skills, capacities and personnel training influencing an enterprise's ability to perceive new ideas, its flexibility and constant improving.

The authors of this article did not set a goal to closely look at the essence of such concept. However, we shall make certain notes directly due to marked euphoria of Russian IBS admirers.

First of all, how can they talk about the balanced system of the management process indices when the IBS deals only with one of its elements namely, feedback indices? Secondly, among the four enterprise performance spheres which according to the IBS developers shall be of the manager's interest include both the object's indices and the management system's indices (that is quite natural). But all at once at the same level with them appear not indices but the factors determining them.

Falling back upon our article's content, we shall accentuate the fact that the elements from the feedback complex in the course of strategic goals settling rather substantially differ from those used in the course of current operating activity.

\section{References}

1. V. P. Silin, R. O. Chernov. Herald of the Moscow University of MIA of Russia 6, (2011)

2. R. S. Kaplan, D. P. Norton, B. Rugelsjoen, Harvard Business Review 88, (2010)

3. A. Volkov, P. Chelyshkov, A. Sedov, Applied Mechanics and Materials 409-410, 1620-1623 (2013)

4. A. Volkov, A. Sedov, P. Chelyshkov, A. Doroshenko, (2014) Applied Mechanics and Materials 580-583, 3231-3233 (2014) 